\title{
Improving rapid multiplication of sweetpotato (Ipomoea batatas L. (Lam) pre-basic seed using sandponics technology in East Africa
}

\author{
Bramwel W. Wanjala ${ }^{1, *,}$, Rajendran Srinivasulu ${ }^{1}$, Phabian Makokha ${ }^{1} \mathbb{D}$, Reuben T. Ssali ${ }^{2}$, \\ Margaret McEwan ${ }^{1}$, Jan F. Kreuze ${ }^{3}$ and Jan W. Low ${ }^{1}$ (D) \\ ${ }^{1}$ International Potato Centre, SSA Regional Office, P.O Box 25171-00603, Nairobi, Kenya, ${ }^{2}$ International Potato Centre, C/O \\ CSIR-Crops Research Institute, P.O Box 3785, Kumasi, Ghana and ${ }^{3}$ International Potato Centre, Avenida La Molina 1895, La \\ Molina. Apartado Postal 1558, Lima, Peru \\ *Corresponding author. Email: bramwelwanjala@yahoo.com
}

(Received 27 March 2019; revised 18 October 2019; accepted 11 December 2019; first published online 30 January 2020)

\begin{abstract}
Sweetpotato (Ipomoea batatas, Convolvulaceae) is an important food crop in Sub-Saharan Africa (SSA). Lack of access to quality sweetpotato planting material after sweetpotato limits utilization of market oriented improved clones and new varieties. Obtaining clean planting material in the right quantity and quality is a challenge in the SSA region. Farmers often obtain planting materials from their own sources with multiple rooting, drawn from a previous crop or neighbors and face the risk of it being infected with sweetpotato viruses. The objective of this study was to examine the economic and physical yield performance of sandponics multiplication method by comparing with conventional soil method using optimal $\mathrm{N}$-nutrient inputs. The performance of five sweetpotato cultivars (Irene, Delvia, Tanzania, Gweri, and Kabode) in the modified prototype sweetpotato nutrient media was evaluated. Vine production utilizing modified sandponics nutrient media with trellised plants was compared to the conventionally used soil media. Analysis of variance indicated that the main effects of cultivar and substrate were highly significant $(p<0.0001)$ for nodes produced, vine multiplication rate (VMR), number of cuttings produced, and vine length. In addition, cultivar by substrate interaction was highly significant at 0.01 probability level for nodes produced, VMR, and vine length. Vine multiplication rate was $33 \%$ higher in the sandponics system compared to the conventional soil method of multiplying sweetpotato vines. Among the cultivars studied, Irene was the most favorable cultivar with a VMR of 65.2 in sand and 45.5 in soil. The cost-effectiveness analysis indicates that the cost per cutting (i.e., 3-4 nodes) produced from sandponics method was $4.6 \mathrm{KSH}$ (US\$ 0.046) as compared to $3.1 \mathrm{KSH}$ (US\$ 0.031) per cutting produced from conventional method. Sandponics system is competitive due to its capability of increased VMRs. However, the optimal number of ratooning needs to be investigated to understand the economies of scale in future research.
\end{abstract}

Keywords: Nutrient media; Pre-basic seed; Rapid multiplication; Sandponics; Sweetpotato vines

\section{Introduction}

Sweetpotato (Ipomoea batatas, family Convolvulaceae) is ranked the seventh most important food crop in global production with an annual production of more than 100 million tonnes (FAO, 2010). It is grown in more than 100 countries in the tropical, subtropical, and temperate regions

\footnotetext{
${ }^{\dagger}$ Current address: Kenya Agricultural and Livestock Research Organisation, Biotechnology Research Institute, P.O Box 14733 00800, Nairobi, Kenya

(c) The Author(s) 2020. This is an Open Access article, distributed under the terms of the Creative Commons Attribution licence (http:// creativecommons.org/licenses/by/4.0/), which permits unrestricted re-use, distribution, and reproduction in any medium, provided the original work is properly cited.
} 
worldwide with Sub-Saharan Africa (SSA) being the second largest producer after Asia. Sweetpotato is considered a food security crop in SSA due to its fast growing period with low input requirements. Most products are derived from the roots, while the vegetative parts can be utilized as vegetable and feed for livestock (Lebot, 2009). Inadequate availability of quality sweetpotato vines limit the utilization of improved and new varieties. Farmers are faced with the challenge of obtaining clean planting material and in the right quantity. Vine cuttings for planting are often obtained from a mature crop in the tropics and pose a challenge in areas with a long dry season which desiccates the foliage. Vine production is carried out in swamps or river beds where vines can be watered for supply of planting material at the beginning of the planting season when rains are expected. Materials sourced in this way are of unknown health status and could be harboring sweetpotato viruses which pose great challenge.

Seed standards and inspection protocols for clonally propagated crops such as sweet potato developed by Food and Agriculture Organization recommend for; multiplication of clean (disease-free) plantlets in laboratories and then in screenhouses for further field multiplication. The Sweetpotato Action for Security and Health in Africa (SASHA) project phase II in collaboration with National Agricultural Research Institutes (NARIs) sweetpotato programmes has been working on the development of business models for sustainable sweetpotato pre-basic seed production to improve the quality of material entering the seed system. A key challenge is to increase pre-basic seed multiplication rates in the screenhouses and reduce production costs (Rajendran et al., 2017). The conventional method currently used utilizes sterilized soil-based substrates. The process of obtaining soil and sterilization by steam generated by diesel is labor intensive, time consuming, and expensive (Rajendran, unpublished). Sandponics system has been postulated to be a viable alternative in sweetpotato pre-basic seed production in screenhouses. The system has been successfully used to produce seed potato mini tubers in aeroponics (Mateus-Rodriguez et al., 2013). However, one limiting factor for adoption of sandponics is the lack of nutrient formulation for sweetpotato. Previous studies by Chuquillanqui et al. (unpublished) using seed potato nutrient formulation demonstrated that sandponics system gave a higher vine production than soil method. Similar results were reported in Malawi, Zambia, and Mozambique (Masamba, Chiona, and Ricardo, personal communication), but the combination of both economic and physical viability of the sandponics compared to the soil method using optimal nutrient media for sweetpotato seed production remains unclear. Therefore, identifying appropriate optimal nutrient media level that could be adapted for rapid sweetpotato vine production in sandponics is therefore necessary to increase pre-basic seed production at a low cost. Nitrogen is the key macroelement for sweetpotato vine production, although nitrogen requirement that maximizes vine production for various sweetpotato varieties was not found in literature (Jiang, 2013). However, most formulas call for 100-200 ppm of nitrogen in the form of $\mathrm{NO}_{3}{ }^{-}$(Jones, 1983). Studies by Jiang (2013) reported a range of 100-300 ppm N to favor sweetpotato vine growth in hydroponics. Study was conducted to explore optimal level of cost-effective $\mathrm{N}$-nutrient solution for sweetpotato vine production through sandponics method by modifying the $\mathrm{N}$-nutrient solution in seed potato nutrient media. A cost-effectiveness analysis was performed to compare relative cost and outcomes of

soil and sandponics vine production systems interventions to identify the most cost effective method of multiplication of sweetpotato vines.

\section{Materials and Methods}

Greenhouse experiments were conducted in November 2016-June 2017 at the International Potato Centre (CIP) research station based at The Kenya Plant Health Inspectorate services (KEPHIS) - Plant Quarantine and Biosecurity Station, Muguga, Kenya. The site is located at $01^{\circ} 12.82^{\prime} \mathrm{S}, 036^{\circ} 37.86^{\prime} \mathrm{E}, 2084 \mathrm{~m}$ asl. 
Table 1. Prototype nutrient media modified from the seed potato media for $1000 \mathrm{I}$

\begin{tabular}{|c|c|c|c|}
\hline \multicolumn{2}{|l|}{ Otazu (2010) } & \multicolumn{2}{|c|}{ Current study } \\
\hline Nutrient & $\mathrm{g} / 1000 \mathrm{~L}$ & Nutrient & $\mathrm{g} / 1000 \mathrm{~L}$ \\
\hline Calcium nitrate ( $17 \%$ Ca $12 \% \mathrm{~N})$ & 295 (35.4 ppm N) & Calcium nitrate ( $17 \%$ Ca $12 \% \mathrm{~N})$ & 576 (69.1 ppm N) \\
\hline $\begin{array}{l}\text { Potassium phosphate } \\
(29 \% \text { K } 23 \% \text { P })\end{array}$ & 170 & $\begin{array}{l}\text { Potassium phosphate } \\
\quad(29 \% \text { K } 23 \% \mathrm{P})\end{array}$ & 170 \\
\hline $\begin{array}{l}\text { Potassium nitrate } \\
\qquad\left(13 \% \mathrm{~K} 13 \% \mathrm{NO}_{3}\right)\end{array}$ & $630(81.9$ ppm N) & $\begin{array}{l}\text { Potassium nitrate } \\
\quad\left(13 \mathrm{~K} \% 13 \% \mathrm{NO}_{3}\right)\end{array}$ & $1111.1(144.4 \mathrm{ppm} \mathrm{N})$ \\
\hline Magnesium sulfate (10\% 13\%) & 615 & Magnesium sulfate ( $10 \% 13 \%)$ & 615 \\
\hline Boron & 1.75 & Microsol B & 1.75 \\
\hline
\end{tabular}

The experimental design was randomized complete block split plot design (RCBSPD). Two production systems were tested: Sandponics and soil (conventional). Each treatment combination (production system ${ }^{\star}$ variety) was replicated 25 times, with each replication being a block. The production system constituted a whole-plot factor, whereas the variety was a subplot factor. The assumption made was that there will be minimal positional or microenvironmental effects in the greenhouse.

Disease-free virus indexed planting materials of cultivars Irene, Delvia, Tanzania, Gweri, and Kabode were used. The cultivars were selected based on their gross morphology as described by Huaman (1991). Soil substrate comprised of top forest soil, cow manure, and gravel in the ratio of $5: 2: 1$. Sterilization was achieved by loading the soil in steam boilers then steaming for 25 min using diesel as source of energy. River sand was used as substrate in the sandponics. Sand was sifted using a screen, soaked for $10 \mathrm{~min}$ in $10 \%$ JIK (sodium hypochlorite), and rinsed five times to remove chlorine, then left overnight on a raised metallic framework to drip off and further allow any chlorine residues to evaporate. Fertigation media was formulated from seed potato mini tuber nutrient media (Table 1). The N-nutrient solution was adjusted upward from 117 to $213 \mathrm{ppm}$ based on previous studies by Chen (2013), while the other nutrient rates were kept constant.

Three-liter plastic pots measuring $17 \mathrm{~cm}$ diameter and $20 \mathrm{~cm}$ height perforated at the base were filled with 4.5 and $5 \mathrm{~kg}$ of sterilized soil and sand, respectively, then placed on plastic plates. Soil and sand filled pots were irrigated and fertigated, respectively, until the pots started leaking on the plates prior to planting. Each soil pot was fertilized with $3 \mathrm{~g}$ of diammonium phosphate (18:46:0). Five cuttings of three nodes were planted in each pot.

Plants were initially irrigated on weekly basis and later on biweekly 20 days after planting. Stage of plant growth and environmental conditions determined the interval between irrigation. Each time a treatment was irrigated until all pots in the same treatment started to leach water from the bottom of the pot on to the collection plate. In contrary, with sand hydroponics, the nutrient solution was placed in a 2001 PVC tank. Five distribution pipes with a common connecting tap released the nutrient solution directly to the base of sweetpotato plants until all pots in the same treatment started to leach nutrient solution from the bottom of the pot on to the collection plate. The frequency of fertigation followed the same criteria as in the conventional system. Plants growing in the conventional soil system were fertilized with $3 \mathrm{~g}$ of urea (46:0:0) per pot at 1.5 months interval. Temperature and relative humidity were monitored by HOBO Data Loggers in the screenhouse. Greenhouse temperatures ranged between 21 and $42{ }^{\circ} \mathrm{C}$ during the day and $11-24^{\circ} \mathrm{C}$ at night.

During growth, plants were trellised using manila strings as vine length increased (Supplementary Figure S1 available online at https://doi.org/10.1017/S0014479719000413) in view of studies which have shown that trellising sweetpotato increased vine production when compared to ratooning (Njoku, personal communication). Insects were monitored and controlled by mounted yellow and blue sticky traps and biweekly spraying with alternating insecticides. Harvesting was done 180 days after planting. At harvesting, vines were cut leaving two nodes from base. 


\section{Data collection and analysis}

Vegetative growth parameters on number of plants harvested, number of nodes produced, number of cuttings (3-4 nodes), and total vine length were recorded. Data on inputs used, main production activities (labor cost), wastage, and value of machinery used during production period and its depreciation values were captured. Collected data were subjected to analysis of variance in Statistical Analysis Software (SAS) version 9.4 (SAS Institute Inc., 2001) using the GLM procedure and means separated by LSD. Comparison of vine multiplication rates (VMRs) in the two systems was done using t-test procedure.

Producing large quantity of sweetpotato early generation seed (EGS) of high-quality seed at low cost is essential for economically viable supply of quality sweetpotato seed. Therefore, the study hypothesized that sandponics sweetpotato vine production costs per three node cutting would be lower than the conventional method. Though there are several methods to analyze the economic viability of the technology (Mateus-Rodriguez et al., 2013), this study tested the hypothesis using cost-effectiveness or least-cost combination method due to nature of the technolgy and experiment. This method is part of constant effect method. The method is normally used in developing countries to deal with intangible benefits. The intangible benefits will be determined on a present worth basis; the least expensive alternative combination of tangible costs that will realize essentially the same intangible benefits (Gittinger, 1985). The cost-effectiveness analysis is used to identify among alternative technologies to determine the most cost-effective means to produce product. Since this study is based on experimental basis, we collected cost data in the sandponics and conventional vine propagation systems based on real-time basis between November 2016 and June 2017. As part of production cost calculation, the experiment was carried out during a crop calendar period of 8 months, and hence the cost estimates were restricted to activities carried out during this production period. The following procedure was followed to gather information on costs for both type of production system: (i) Selecting team members who are directly involved in the production activities, (ii) drawing a crop calendar, (iii) mapping out operational activities and inputs, and (iv) mapping out costs information and share of allocation of inputs. Data collection questionnaire was classified into micro-log sheet, which monitors daily activities in the experiment for each labor. Once data were recorded in the micro-log sheet for each laborer, it was transferred to macro-log sheet and then transferred to cost calculation sheet to built into Microsoft Office Excel program. The data were monitored for each production activities separately for both sandponics and conventional production system using micro- and macro-lag sheet on real-time basis.

The cost was classified into major two categories, namely, variable and fixed costs. Variable costs included labor, inputs, and consumable costs. The cost of labor was estimated based on wage rate per day and number of man-days involved by laborers in the production activities. The input costs dealt with quantity of inputs used and cost of inputs used in the both production systems. Finally, consumables were costs also included as part of variable costs. Under the fixed cost, we identified the type of equipment used for producing sweetpotato seed during the experiment. It is defined as those costs that occur regardless of how much you produce. Once we identified the equipment, we also identified equipment life span of the equipment (i.e., number of years). The fixed cost was estimated by considering depreciation costs, interest on average investment, life span of the equipment, insurance and taxes. Adding up both variable and fixed costs, the total cost of production was estimated. In addition to total production costs, the study also included $10 \%$ overhead costs because this experiment was conducted at KEPHIS where water and electricity were provided by the government. Further, the study also monitored pre- and postharvest losses and these were accounted for in the total costs. Apart from estimating cost of production for both systems, the study also estimated cost of producing sterilized sand and soil and included in the cost of sandponics and conventional production system, respectively. The costs were considered for variable lifetime ( 8 months) and amortized during production 
Table 2. Analysis of variance (ANOVA) for outcome indicators

\begin{tabular}{lccccc}
\hline Source of variation & DF & $\begin{array}{c}\text { No. of nodes } \\
\text { produced }\end{array}$ & $\begin{array}{c}\text { Vine multiplication } \\
\text { rate }\end{array}$ & $\begin{array}{c}\text { No. of cuttings per } \\
\text { vine }\end{array}$ & $\begin{array}{c}\text { Total vine } \\
\text { length }\end{array}$ \\
\hline Substrate & 1 & $114318.9^{\star \star}$ & $12709.2^{\star \star}$ & $245.4^{\star \star}$ & $4936186.6^{\star \star}$ \\
Variety & 4 & $24205.6^{\star \star}$ & $2689.6^{\star \star}$ & $46.5^{\star \star}$ & $1341223.2^{\star \star}$ \\
Substrate $\times$ Variety & 4 & $6161.1^{\star \star}$ & $683.6^{\star \star}$ & 2.1 & $134814.8^{\star \star}$ \\
Error & 240 & 1226.7 & 136.3 & 5.8 & 31973.4 \\
\hline
\end{tabular}

*, ** significant at 0.05 and 0.01 respectively; ns = not significant.

Table 3. Mean comparison of vine yield growth parameters in sand and soil substrate

\begin{tabular}{lcccc}
\hline Vine yield trait & Sandponics & Soil & $t$ & $p$ \\
\hline No. of nodes produced & $150.6 \pm 9.0$ & $107.8 \pm 5.2$ & 8.3 & $<0.0001$ \\
Vine multiplication rate & $50.2 \pm 3.0$ & $35.9 \pm 1.7$ & 8.3 & $<0.0001$ \\
No. of cuttings per vine & $8.0 \pm 0.4$ & $6.0 \pm 0.4$ & 6.2 & $<0.0001$ \\
Total vine length $(\mathrm{cm})$ & $827.7 \pm 50.8$ & $546.6 \pm 30.4$ & 9.5 & $<0.0001$ \\
\hline
\end{tabular}

Table 4. Mean comparison for varieties

\begin{tabular}{lcccc}
\hline Variety & $\begin{array}{c}\text { No. of nodes } \\
\text { produced }\end{array}$ & $\begin{array}{c}\text { Vine multiplication } \\
\text { rate }\end{array}$ & $\begin{array}{c}\text { No. of cuttings } \\
\text { per vine }\end{array}$ & $\begin{array}{c}\text { Total vine } \\
\text { length }(\mathrm{cm})\end{array}$ \\
\hline Irene & $160.2 \mathrm{~A}$ & $53.4 \mathrm{~A}$ & $6.1 \mathrm{CB}$ & $854.1 \mathrm{~A}$ \\
Delvia & $134.6 \mathrm{~B}$ & $44.9 \mathrm{~B}$ & $8.0 \mathrm{~A}$ & $784.1 \mathrm{BA}$ \\
Tanzania & $129.7 \mathrm{~B}$ & $43.2 \mathrm{~B}$ & $6.9 \mathrm{~B}$ & $736.1 \mathrm{~B}$ \\
Gweri & $122.3 \mathrm{~B}$ & $40.7 \mathrm{~B}$ & $5.9 \mathrm{C}$ & $627.3 \mathrm{C}$ \\
Kabode & $99.2 \mathrm{C}$ & $33.1 \mathrm{C}$ & $7.9 \mathrm{~A}$ & $434.1 \mathrm{D}$ \\
$p$ value & $<0.0001$ & $<0.0001$ & $<0.0001$ & $<0.0001$ \\
LSD (\%) & 13.8 & 4.6 & 0.9 & 70.4 \\
\hline
\end{tabular}

Means with different letters in the same column are significantly different at $95 \%$ confidence level.

season. Total costs of production were estimated in each production system, and the total cost of production (TPC, KSH per system) for each system was divided by the total number of cuttings node in each system to get average cost of production per node.

\section{Results}

The main effects of substrate and variety on all the vine vegetative growth parameters studied were significant at $p<0.0001$ (Table 2), whereas interaction of substrate by cultivar effect was also significant (0.01) for number of nodes produced, VMRs, and total vine length. A comparison in the means of total number of nodes produced, number of cuttings harvested, vine length, and VMR in the two systems using a t-test indicated that the means of all the vine traits studied were significant at $p<0.0001$ (Table 3). It was evident that sandponics produced significantly higher yields considering all the vine traits measured compared to the conventional soil system (Table 3 ). Irene and Kabode were varieties that recorded the highest and lowest yields in that order considering number of nodes, VMRs, and vine length with figures of 160.2/99.2, 53.4/33.1, and $854.1 / 434.1 \mathrm{~cm}$ (Table 4 ). In addition, the interaction of substrate by variety on nodes produced, VMR, and total vine length was statistically significant at $p<0.01$ (Table 2). Data further showed that interaction of sandponics with all the five varieties produced higher number of nodes, VMRs, as well as total vine length compared to the conventional soil system (Table 5). 
Table 5. Mean comparison for the effect of substrate and variety combination

\begin{tabular}{llccc}
\hline Substrate & Variety & No. of nodes produced & Vine multiplication rate & Total vine length $(\mathrm{cm})$ \\
\hline \multirow{2}{*}{ Sand } & Irene & $195.8 \mathrm{~A}$ & $65.2 \mathrm{~A}$ & $1007.8 \mathrm{~A}$ \\
& Tanzania & $156.9 \mathrm{~B}$ & $52.3 \mathrm{~B}$ & $918.8 \mathrm{BA}$ \\
& Gweri & $145.9 \mathrm{~B}$ & $48.6 \mathrm{~B}$ & $803.4 \mathrm{~B}$ \\
& Delvia & $143.2 \mathrm{~B}$ & $47.7 \mathrm{~B}$ & $920.4 \mathrm{BA}$ \\
& Kabode & $111.2 \mathrm{C}$ & $37.1 \mathrm{C}$ & $487.8 \mathrm{C}$ \\
p value & & $<0.0001$ & $<0.0001$ & $<0.0001$ \\
LSD (\%) & & 23.9 & 8.0 & 123.7 \\
Soil & Irene & $124.6 \mathrm{~A}$ & $41.5 \mathrm{~A}$ & $700.4 \mathrm{~A}$ \\
& Tanzania & $102.6 \mathrm{~B}$ & $34.2 \mathrm{~B}$ & $647.8 \mathrm{~A}$ \\
& Gweri & $98.7 \mathrm{CB}$ & $32.9 \mathrm{CB}$ & $553.4 \mathrm{~B}$ \\
& Delvia & $126.0 \mathrm{~A}$ & $42.0 \mathrm{~A}$ & $451.1 \mathrm{C}$ \\
& Kabode & $87.2 \mathrm{C}$ & $29.0 \mathrm{C}$ & $380.4 \mathrm{D}$ \\
P value & & $<0.0001$ & 40.0001 & $<0.0001$ \\
LSD (\%) & & 14.0 & 4.7 & 69.0 \\
\hline
\end{tabular}

Means with different letters in the same column are significantly different at $95 \%$ confidence level.

On the account of varietal performance in the two systems, Irene produced the highest number of nodes, whereas Kabode produced the lowest number recording figures of 195.8/124 and 111.2/87.2 in sandponics and soil, respectively.

The cost-effectiveness analysis results indicated that the cost per cutting (i.e., 3-4 nodes) produced from sandponics method is $4.6 \mathrm{KSH}$ (US\$ 0.046$)^{1}$ as compared to $3.1 \mathrm{KSH}$ (US\$ 0.031$)^{1}$ per cutting produced from conventional method. As per variety concern, Irene variety is a cost-effective option within sandponics method (i.e., $3.8 \mathrm{KSH}$ per cutting), as well as within conventional method (i.e., $2.9 \mathrm{KSH}$ per cutting). Within sandponics experiment, the maximum cost of production per cutting for variety Kabode was reported to be $6.4 \mathrm{KSH}$. Similarly, in the conventional method, the maximum cost of production per cutting for Kabode variety was reported to be $4.6 \mathrm{KSH}$.

\section{Discussion}

Multiplication of sweetpotato vines in sand with fertigation, also known as sandponics, gives significantly higher yields either as number of nodes produced, number of cuttings, vine length, and VMRs, compared to the conventional soil method. For instance, the current study shows that sweetpotato VMR was $33 \%$ higher in the sandponics compared to the conventional soil method. The high vine yields in sandponics system may be associated with the precise control of the nutrient solution that provides optimal growing condition. Soilless systems for production of different crops have several benefits compared with the soil production system (Rostami and Movahedi, 2016; Soroushzadeh, 2012), which agrees with our results. The results from this study show that using the sandponics system has the potential to improve the VMR of sweetpotato pre-basic seed.

Significant varietal differences in the number of nodes produced, VMR, number of cuttings, and the total vine length could be attributed to marked phenotypic differences and production type as reported by Lam (2016). Furthermore, differences in growth morphology of varieties as described by Huaman (1991) in relation to plant type as either erect, semi-erect, spreading, or extremely spreading as well as variations in vine internode categorized as very short, short, intermediate, long, and very long influenced the vine yield traits studied statistically among the sweetpotato varieties. For instance, cultivar Irene had the highest VMR, total vine length,

${ }^{1}$ Exchange rate $1 \mathrm{US} \$=100 \mathrm{KSH}$ in year 2018. 
and produced the highest number of nodes, whereas cultivar Kabode recorded the least VMR, total vine length, and number of nodes (Table 4). Irene is an early cultivar with erect growth and tends to produce prolific sprouts but has a short vine internode, this could be the reason why it produced high number of nodes, VMR, and total vine length but lower number of cuttings per vine. On the other hand, cultivar Kabode is erect with very short internode, and this could be the reason it produced the lowest number of nodes, VMR, and total vine length but high number of cuttings per vine. More so, the differences in the yields of vine traits could also have been marked by the genotypic differences of cultivars as reported in other crops like potato (Rostami and Movahedi, 2016). Among the cultivars studied, Irene was the most favorable cultivar, and its VMR and total vine length were 1.6 and 1.4 times higher in the sandponics system than in the conventional system, respectively (Table 5). This could be attributed to the controlled optimal nutrient media in the sandponics as well as the phenotypic and genotypic nature of cultivar Irene characterized by earliness, prolific sprouting, and short vine internode.

The financial cost-effectiveness analysis was conducted, and the results indicated that the current sandponics protocol was not cost effective compared with the conventional method. The reasons for this include (i) cost of inputs (chemicals) was expensive compared with the conventional method and (ii) cost of irrigation is higher than with the conventional method due to the higher frequency of irrigation required for sandponics. However, there is a scope in future research to reduce the costs of production by increasing production period through increasing optimal number of harvests and also keeping the vigor of the vine yield. This will increase the economies scale. In addition, genotype also can be changed to understand the yield pattern in both production systems.

\section{Conclusions and Recommendations}

The sandponics system offers a viable option for sweetpotato pre-basic seed production due to increased VMRs; however, the cost of production in the sandponics method is more expensive compared to the soil method. Therefore, further studies are required to explore alternative sources of fertilizers that are locally available with examples such as manure and compost filtrates that are less costly to make sandponics a cost-effective technology. Trellising practice was used in this trial; however, studies on ratooning to establish the optimal number of ratoons in both methods ought to be conducted and compared with trellising. The number of ratoons could be extended to increase the economies of scale. Moreover, a higher sample size is required from a larger cultivated area (or conduct this experiment in a bigger screenhouse rather than small greenhouse); utilizing pots (instead of benches or beds) may not be cost effective in a crop with a short life cycle.

Acknowledgements. The International Potato Center (CIP) funded this study through the Sweetpotato Action for Security and Health in Africa (SASHA) project, support by the Bill \& Melinda Gates Foundation, Seattle WA [OPP1019987]. The authors appreciate the Kenya Plant Health Inspectorate Services-Plant Quarantine and Biosecurity Station (KEPHIS-PQBS) Muguga for screen house facilities. We express special thanks of gratitude to the Director General, Kenya Agricultural and Livestock Research Organization (KALRO) for granting leave of absence to the first author.

Financial support. None.

Supplementary material. For supplementary material for this article, please visit https://doi.org/10.1017/S0014479719000413

\section{References}

FAO (2010). Quality Declared Plant Material. Protocols and Standards for Vegetatively Propagated Crops. Rome-Italy: Food and Agriculture Organization of the United Nations. 126p.

Gittinger J.P. (1985). Economic Analysis of Agricultural Projects (English). Unnumbered series; no. UNN 76. Washington, DC: World Bank. http://documents.worldbank.org/curated/en/584961468765021837/Economic analysis-of-agricultural-projects.

Huaman Z. (1991). Descriptors for Sweetpotato. Rome, Italy: CIP-AVRDC-IBPGR. pp. 1-134. 
Chen J. (2013). Sweetpotato Root quality in response to Abiotic Factors and Maximizing Greenhouse Plant production by adjusting fertilizer application rates. MSc Thesis, North Carolina State University.

Jones J. B. Jr. (1983). A Guide for the Hydroponic and Soilless Culture Grower. Beaverton, OR: Timber Press, pp. 124.

Lam V. (2016). Agricultural potential of sweetpotato (Ipomoea batatas, L. (Lam)) for forage production. Livestock Research for Rural Development 28. Available at http://www.lrrd.org/lrrd28/6/lam28101.html (accessed 6 June 2017).

Lebot V. (2009). Tropical root and tuber crops: cassava, sweetpotato, yams and aroids. In Atherton J. and Rees A. (eds), Crop Production Science in Horticulture Wallingford, UK: CAB books, CABI. p. 17.

Mateus-Rodriguez J.R, De Haan S., Andrade-Piedra J.L, Maldonado L., Hareau G., Barker I., Chuquillanqui C., Otazú V., Frisancho R., Bastos C., Pereira A.S., Medeiros C.A., Montesdeoca F. and Benítez J. (2013). Technical and economic analysis of aeroponics and other systems for potato mini-tuber production in Latin America. American Journal of Potato Research 90, 357-368.

Otazu V. (2010). Manual on Quality Seed Potato Production using Aeroponics. Lima, Peru: International Potato Center (CIP), $44 \mathrm{p}$.

Rajendran S., Kimenye L.N. and McEwan M. (2017). Strategies for the development of the sweetpotato early generation seed sector in eastern and southern Africa. Open Agriculture 2, 236-243.

Rostami M. and Movahedi Z. (2016). Evaluation the effects of Naphthalene acetic acid (NAA) on morpho-physiological traits of valerian (Valeriana officinalis L.) in aeroponic system. Iranian Journal of Plant Physiology 6, 1751-1759.

SAS Institute (2001). SAS/STAT User's Guide. 9.4. Version. Cary, NC: SAS Institute Inc.

Soroushzadeh A. (2012). Comparison of aeroponics and conventional soil systems for potato mini-tubers production and evaluation of their quality characters. Journal of Plant Physiology and Breeding 2, 13-25.

Cite this article: Wanjala BW, Srinivasulu R, Makokha P, Ssali RT, McEwan M, Kreuze JF, and Low JW (2020). Improving rapid multiplication of sweetpotato (Ipomoea batatas L. (Lam) pre-basic seed using sandponics technology in East Africa. Experimental Agriculture 56, 347-354. https://doi.org/10.1017/S0014479719000413 